\title{
Genomic characterization, high-density mapping and anchoring of DArT markers to the reference genome of Eucalyptus
}

\author{
César Petroli i*, Carolina Sansaloni ${ }^{1}$, Jason Carling ${ }^{2}$, Eva M C Mamani ${ }^{1}$, Dorothy A Steane ${ }^{3}$, Alexander A Myburg ${ }^{4}$, \\ René E Vaillancourt ${ }^{3}$, Andrzej Kilian², Georgios J Pappas ${ }^{5}$, Orzenil Bonfim da Silva ${ }^{5}$, Dario Grattapaglia ${ }^{5}$
}

From IUFRO Tree Biotechnology Conference 2011: From Genomes to Integration and Delivery

Arraial d'Ajuda, Bahia, Brazil. 26 June - 2 July 2011

\section{Background}

Genetic linkage maps have been essential tools to examine the inheritance of qualitative and quantitative traits, to carry out comparative mapping and to provide markers for molecular breeding applications. Linkage maps for species of Eucalyptus have been reported for several pedigrees using different molecular marker technologies [1]. However improved marker density, throughput and transferability across species are necessary to increase resolution of current maps for a variety of genomic applications. We report the development of a high density linkage map for Eucalyptus based on microsatellites and DArT (Diversity Arrays Technology) markers generated by a standardized genotyping microarray [2]. DNA probes that constitute the DArT microarray were sequenced and positioned on the reference Eucalyptus genome providing information about their sequence content, their distribution relative to annotated genes as well as the relationship between physical and recombination distance in the Eucalyptus genome.

\section{Methods}

Map construction was carried out using an F1 progeny of 177 individuals derived from a cross between E.grandis and E.urophylla. Genomic representations of both parents and their F1 offspring were produced with the same complexity reduction method used to prepare the library (PstI/TaqI) generating the 'targets' for hybridizing to the arrays. Microarray imaging, data extraction

\footnotetext{
* Correspondence: cesar@cenargen.embrapa.br

'EMBRAPA Genetic Resources and Biotechnology - EPqB Final W5 Norte 70770-917 Brazilia DF and Dep. Cell Biology, Universidade de Brazilia - UnB, Brazil

Full list of author information is available at the end of the article
}

polymorphism detection and marker scoring were carried out using DArTSoft v.7.44 (http://www.diversityarrays.com/). Polymorphic markers were filtered according to reproducibility, quality parameter $(\mathrm{Q})$ and marker call rate as described earlier [2]. An integrated linkage map was constructed with JoinMap v3.0 [3] using a framework map of previously mapped fully informative anchor microsatellites. All 7,680 DNA probes that constitute the current DArT genotyping microarray were Sanger sequenced. Redundancy analysis was carried out at the sequence level using a 50bp minimum overlap, $98 \%$ identity, and allowing for $10 \%$ mismatch and gap size of one bp. These DArT probes were mapped on the annotated Eucalyptus reference genome as available in Phytozome. Distribution of DArT probes and mapped DArT markers relative to the predicted gene models was carried out by dividing the genome in $500 \mathrm{kbp}$ bins corresponding approximately to a $1 \mathrm{cM}$ recombination fraction.

\section{Results}

A segregation ratio filtering (both for 1:1 and 3:1 markers) together with a relaxed call rate threshold $>50 \%$ were initially applied to include the largest number of potentially mappable markers. A total of 4,271 DArT markers segregated $1: 1$ and 1,572 segregated 3:1. The complete dataset with 6,065 markers (5,843 DArT and 222 microsatellites) was submitted to a linkage analysis resulting in eleven groups at LOD $\geq 15$ with a total of 2,484 markers. A subset of 1,032 markers positioned at high likelihood for ordering (864 DArTs and 168 microsatellites) provided a framework map with $1,176 \mathrm{cM}$ and an average recombination distance between consecutive markers of $1.15 \mathrm{cM}$. When all the 2,484 mapped markers 
were fitted, the total recombining genome length increased to $1,303 \mathrm{cM}$ with a resolution of $0.6 \mathrm{cM}$. A redundancy analysis of the 6,918 DArT probes for which sequences could be obtained resulted in 4,583 unique sequences (66\%). The estimated redundancy of $34 \%$ represents a useful resource by providing alternative probes for detecting polymorphism in the same genomic region in different individuals. A total of 6,480 probes $(93.7 \%)$ were confidently mapped onto the reference genome; 4,189 of them (65\%) mapped to single positions while the remaining 2,291 probes mapped to a second position with a relatively high suboptimal alignment score and were therefore considered mapped at lower confidence. About $50 \%$ of these low confidence mapping $(1,026)$ actually mapped to a sequence position containing a repeat element which might explain the mapping result. A total of 438 DArT probes could not be mapped to the current assembly. These DArT probes might further improve the current genome version by including some yet unassembled genome contigs. A total of 1,987 linkage mapped DArT markers for which sequence was available were positioned relative to the 41,208 gene models in the current genome, distributed in $500 \mathrm{kbp}$ bins providing an average of $1.6 \pm 2.4$ DArT markers for the $34 \pm 15$ gene models present in each genome bin. Interestingly a total of 4,663 DArT probes (67\%) mapped at less than ten basepairs from the nearest gene model and only 76 probes mapped at more than $10 \mathrm{kbp}$. The largest distance from a DArT probe to the next gene was only $156 \mathrm{kbp}$ and a modest although highly significant coincidence across the whole genome was seen between the number of DArT markers and the number of gene models (Spearman rank correlation $\mathrm{R}=0.33 \mathrm{p}<0.00000$ ).

\section{Conclusions}

The linkage map presented in this work was used to aid the ordering of contigs during the assembly of the Eucalyptus grandis genome currently available through the JGI Phytozome website. This map, together with other parallel mapping efforts that used this same genotyping platform have provided between 2,000 and 3,000 segregating markers irrespective of species of Eucalyptus. The mapping density achieved with the Eucalyptus DArT microarray provides unprecedented opportunities for comparative mapping across pedigrees, high resolution QTL analysis and molecular breeding applications across species of the genus. We have shown that not only the DArT marker sequences are highly enriched for genes, but that their distribution relative to the predicted gene models provides an extremely efficient tool to specifically tag genes at distances within the extent of LD in typical breeding populations. The use of this standardized high-throughput genotyping platform will therefore be instrumental to implement genome-wide selection strategies and positional cloning efforts in multiple Eucalyptus species.

\section{Acknowledgments}

This work was supported by the Brazilian Ministry of Science and Technology through CNPq grant 577047/2008-6 and FAP-DF Grant NEXTREE 193.000.570/2009 and EMBRAPA Macroprogram 2 project grant 02.07.01.004

\section{Author details}

${ }^{1}$ EMBRAPA Genetic Resources and Biotechnology - EPqB Final W5 Norte 70770-917 Brazilia DF and Dep. Cell Biology, Universidade de Brazilia - UnB, Brazil. ${ }^{2}$ Diversity Arrays Technology Pty Ltd. 1 Wilf Crane Crescent, Yarralumla, ACT 2600, Australia. ${ }^{3}$ School of Plant Science and CRC for Forestry, University of Tasmania, Private Bag 55. Hobart, Tasmania 7001. Australia. ${ }^{4}$ Department of Genetics, Forestry and Agricultural Biotechnology Institute (FABI). University of Pretoria. Pretoria. 0002. South Africa. ${ }^{5}$ EMBRAPA Genetic Resources and Biotechnology - EPqB Final W5 Norte 70770-917 Brazilia DF, Brazil.

Published: 13 September 2011

\section{References}

1. Grattapaglia D, Kirst M: Eucalyptus applied genomics: from gene sequences to breeding tools. New Phytologist 2008, 179(4):911-929.

2. Sansaloni CP, Petroli CD, Carling J, Hudson CJ, Steane DA, Myburg AA, Grattapaglia D, Vaillancourt RE, Kilian A: A high-density Diversity Arrays Technology (DArT) microarray for genome-wide genotyping in Eucalyptus. Plant Methods 2010, 6:16.

3. Van Ooijen J, Voorrips R: JoinMap 3.0 software for the calculation of genetic linkage maps. Wageningen, the Netherlands: Plant Research Internation; 2001.

doi:10.1186/1753-6561-5-S7-P35

Cite this article as: Petroli et al:: Genomic characterization, high-density mapping and anchoring of DArT markers to the reference genome of Eucalyptus. BMC Proceedings 2011 5(Suppl 7):P35.

\section{Submit your next manuscript to BioMed Central and take full advantage of: \\ - Convenient online submission \\ - Thorough peer review \\ - No space constraints or color figure charges \\ - Immediate publication on acceptance \\ - Inclusion in PubMed, CAS, Scopus and Google Scholar \\ - Research which is freely available for redistribution \\ Submit your manuscript at www.biomedcentral.com/submit}

